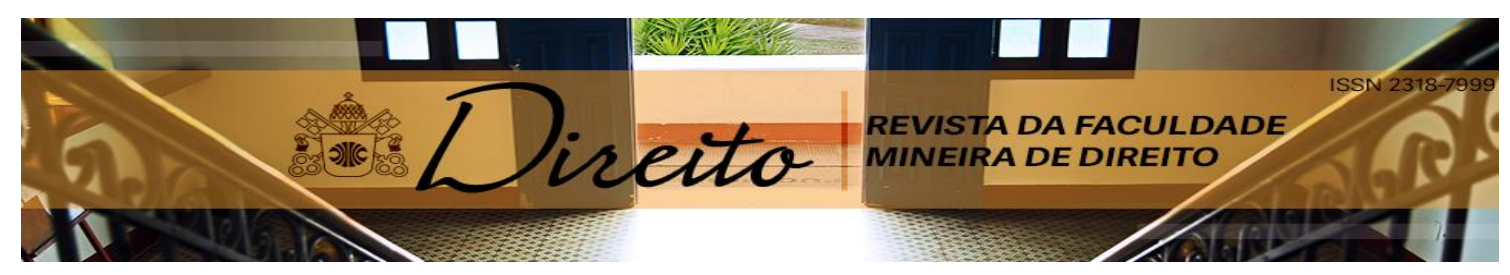

\title{
"TUPI, OR NOT TUPI": A NECESSÁRIA E DEFINITIVA ADAPTAÇÃO DA TEORIA DOS PRECEDENTES AO BRASIL
}

\author{
"TUPI, OR NOT TUPI": THE REQUIRED AND DEFINITIVE ADAPTATION OF \\ PRECEDENTS THEORY TO BRAZIL.
}

Tainá Aguiar Junquilho'

Geovany Cardoso Jeveaux ${ }^{2}$

\begin{abstract}
Resumo
Este ensaio busca analisar as mudanças trazidas pelo Código de Processo Civil de 2015 (CPC/15), no contexto da teoria dos precedentes. Seriam essas mudanças capazes de alcançar a integridade do sistema judicial? Realizou-se análise dos dispositivos nucleares acerca dos precedentes no CPC/15 e revisão de literatura sobre o tema. Assim, pôde-se concluir que, a partir desse novo marco, os juízes devem repensar a aplicação desta teoria com base em fundamentos sólidos, respeitando as nuances do caso concreto, de maneira que se faça possível adaptar a Teoria de precedentes ao Brasil, inspirando-se analogicamente ao que Oswald de Andrade chamou de "antropofagia".

Palavras-Chave: Código de processo civil de 2015. Teoria dos precedentes. Antropofagia.
\end{abstract}

\begin{abstract}
This essay tries to analyze the changes brought by 2015 Code of Civil Procedure (CCP/15), in the context of precedents theory. Are those changes capable to improve the integrity in the judicial system? By conducting, an analysis of what nuclear articles of CCP/15 proposes about precedents and a literature review on the topic. So, it can be concluded that judges should rethink the application of this theory, based on solid grounds, respecting the nuances of the concrete case, in a way that makes it possible to adapt the Theory of Precedents to Brazil, inspired in analogy to what Oswald de Andrade called "anthropophagy".

Key-words: 2015 code of civil procedure. Precedents theory. Anthropophagy.
\end{abstract}

Artigo recebido em 03 de setembro de 2016 e aprovado em 11 de novembro de 2016.

1 Mestre em Direito pela Universidade Federal do Espírito Santo, Vitória, Espírito Santo, Brasil.

2 Doutor em Direito pela Universidade Gama Filho, Professor adjunto II da Universidade Federal do Espírito Santo, Vitória, Espírito Santo, Brasil. 
O Brasil tem, paulatinamente, positivado diversos instrumentos - como as Súmulas Vinculantes, a Repercussão Geral, a Reclamação, entre outros - que possibilitam a aplicação da teoria dos precedentes (ZANETI JÚNIOR, 2016). Porém, a análise da forma como esses mecanismos processuais vêm sendo empregados, parece sugerir o desvirtuamento ou o distanciamento da adoção de um adequado modelo de precedentes.

"Comumente, um bom exemplo disso, é o argumento da utilização da 'doutrina dos precedentes', descrito por razões de ordem prática: o excesso de processos" (TOVAR; MOREIRA, 2016, p. 2). Quando, de fato, muito mais que a visão de necessária superação das metas de julgamento, ou da redução de carga processual, com os precedentes busca-se a integridade do direito, que não deve ser entendida como garantia de uniformidade, mas como desafio posto aos juízes de acolher a noção de que o direito é estruturado por um complexo "coerente de princípios sobre a justiça, a equidade e o devido processo legal adjetivo e pedeIhes que os apliquem nos novos casos que se lhes apresentem, de tal modo que a situação de cada pessoa seja justa e equitativa segundo as mesmas normas". (DWORKIN, 1999, p.291).

A partir desse contexto, este trabalho busca a antropofagia da teoria dos precedentes. Entendida como necessária importação responsável e adaptação imperiosa da teoria dos precedentes aos elementos tradicionais da jurisdição brasileira. Baseia-se a necessidade no texto "Manifesto Antropófago" de Oswald de Andrade (1928). Traz-se à tona a antropofagia como "um convite para a crítica e ao pensamento antes do uso [...] sem um pensamento consciente das singularidades sociológicas e históricas do Brasil, não é possível fazer transplantes ou sequer construções jurídicas" (SIQUEIRA, p. 306).

A investigação tem grande relevância no contexto brasileiro. Isso porque, a complexidade na recepção da teoria dos precedentes, construída ao longo do desenvolvimento histórico dos países de common law ao Brasil é tarefa que exige estudos que internalizem e solidifiquem as bases para sua correta compreensão e aplicação. O momento também torna-se propício, tendo em vista a recente entrada em vigor do Novo Código de Processo Civil, o qual traz inúmeras técnicas que intentam viabilizar a aplicação de um modelo de precedentes vinculantes tipicamente brasileiro, de modo que toda investigação acerca dos novos e renovados institutos faz-se imprescindível.

Desse modo levanta-se a seguinte discussão: o Código de Processo Civil de 2015 (CPC/15) trouxe avanços no campo dos precedentes, capazes de proporcionar uma perspectiva de êxito na tarefa de alcançar a integridade no Direito?

\section{O NOVO PARADIGMA PROCESSUAL CIVIL BRASILEIRO E A NECESSÁRIA ANTROPOFAGIA DA CULTURA DOS PRECEDENTES}

"Só a ANTROPOFAGIA nos une. Socialmente. Economicamente. Filosoficamente". (ANDRADE, 1928). O ideal antropofágico trazido por Oswald de Andrade no Modernismo em sua obra o "Manifesto Antropófago", é modelo à luz do qual pode-se inspirar a teoria processual para a compreensão da inserção da teoria dos precedentes no Brasil. 
O uso da literatura é oportuno artifício que auxilia na compreensão de fenômenos jurídico-culturais. Diante da noção de que a realidade é conceito socialmente concebido a partir da interpretação (CÁRCOVA, 2008), a utilização de obra Oswaldiana que marcou o desenvolvimento cultural brasileiro traz à discussão proveitosos elementos que podem subsidiar a apreensão do "real".

O “Manifesto Antropógafo", segundo Júlio Diniz (2007), é criado em 1928 por Oswald de Andrade, após seu contato com o quadro "Abaporu", recebido de Tarsila do Amaral, sua esposa e artista modernista. A partir daí, cria-se o Clube da Antropofagia e a Revista de Antropofagia, em que se publicavam os ideais antropofágicos e no qual se divulgou o referido Manifesto.

Por meio da utilização do caráter simbólico do ritual indígena antropofágico, Oswald de Andrade propõe que, "só a antropofagia nos une". Ou seja, que se deve assimilar o que vem de fora, incorporar as influências estrangeiras, mas sem perder de vista os predicados originais que dão identidade ao povo brasileiro. Assim,

[...] Oswald traz para o solo arenoso da discussão cultural da época a releitura do conceito de antropofagia como um processo inevitável de assimilação crítica das ideias e modelos europeus, devorando, deglutindo e degustando o que vem de fora, sem se subordinar às dicotomias nacional/estrangeiro, modelo/cópia. Nas suas próprias palavras: "Só interessa o que não é meu. Lei do homem. Lei do antropófago" (DINIZ, 2007, p. 2).

Há, portanto, o reconhecimento da importância da assimilação das peculiaridades culturais estrangeiras. Entretanto, afirma-se a necessidade de que sejam preservadas, ressaltadas e incorporadas as idiossincrasias da tradição brasileira nesse complexo processo de 'deglutição'. Nesse sentido,

[...] Sob a perspectiva Oswaldiana e selvagem, a antropofagia preconiza uma espécie de transubstanciação na qual aquele que é o devorador se altera no devorado: "trata-se apenas da transformação do tabu em totem, isto é, do limite da negação em elemento favorável" (Andrade, 1976). A "morte" e "devoração" do outro recria o próprio; dentro desta perspectiva, o discurso ressentido das relações coloniais torna-se discurso produtivo de identidades (ALMEIDA, 2005, p. 4).

Ingerir o outro significa, dessa forma, enxergá-lo como aquele que pode proporcionar enriquecimento cultural, transformação de valores e qualidades. É exercício de alteridade, de incorporar as particularidades do colonizador, às peculiaridades próprias do colonizado devorador. Como analisa Generoso (2013), a concepção antropofágica Oswaldiana deve ser encarada sob uma feição bilateral. É dizer, aquele que recebe influências culturais, também é "agente do processo" transformador (GENEROSO, 2013, p. 164).

A partir de uma abordagem que explicita diversos conceitos antropológicos de "cultura", Laraia (2007) defende que essa, está intimamente ligada a compreensão de que existem símbolos compartilhados pelos membros do sistema cultural. Na noção de partilha dos signos e 
símbolos por uma comunidade, não se pode olvidar o fenômeno da "difusão cultural". Acerca desse processo,

[...] Não resta dúvida que grande parte dos padrões culturais de um dado sistema não foram criados por um processo autóctone, foram copiados de outros sistemas culturais. A esses empréstimos culturais a antropologia denomina difusão. Os antropólogos estão convencidos de que, sem a difusão, não seria possível o grande desenvolvimento atual da humanidade (LARAIA, 2007, p. 105)

A intensa imbricação dos aspectos da tradição common law ao Brasil é processo natural de difusão cultural. Ciente desse processo de difusão é que deve o País estar atento às implicações da importação da teoria dos precedentes ao cotidiano da atividade judicial. A antropofagia, torna-se oportuna diante desse contexto em que juristas, crendo na relativa autonomia do direito, "aplicam teorias importadas ou simplesmente ignoram as singularidades brasileiras". (SIQUEIRA, 2016, p.305).

É notável que a teoria dos precedentes vem sendo paulatinamente recepcionada pelo sistema jurídico brasileiro, mas essa introdução ainda carece de ajustes em sua aplicação prática. A recepção cultural ainda merece diversas adaptações. Barbosa Moreira (2005, p. 16), em texto sobre os riscos da aplicação da teoria dos precedentes no País, questiona aos leitores se "levada às últimas consequências, ela não poderá servir de instrumento àquilo que em certos setores se tem designado por 'neocolonialismo'".

Nesse aspecto, é interessante observar já de início que a teoria dos precedentes tem envolvido o uso de diversos termos em latim ou em inglês, como "ratio decidendi", "signaling", "obiter dictum", "overruling", para citarem-se alguns. Ora, a receptibilidade da teoria e sua compreensão, perpassa o campo da linguagem. A utilização de termos em português, língua nativa do país, é fator importante que facilita o trabalho com as expressões.

Faz parte do processo de acolhimento cultural e simplifica a compreensão da teoria 0 uso de expressões genuinamente portuguesas e sem arcaísmos ou 'estrangeirismos'. O uso da língua nativa é fator que, inclusive, facilita o acesso à justiça. Conforme denunciam Andrade e Bussinger (2006, p.23)

[...] Uma queixa comum, existente na sociedade, é concernente à distância que existe entre os jurisdicionados e os magistrados. Tal distanciamento seria promovido, entre outros fatores, pela linguagem jurídica, quer seja escrita quer seja oral, que estaria permeada de termos técnicos, latinismos, enfim, uma linguagem erudita. Em razão disso, as pessoas interessadas em uma ação judicial se viam afastadas, de certa forma, da sua demanda.

O próprio "Manifesto Antropófago" já revelava a situação, quando Oswald de Andrade (1928) ironiza "Perguntei a um homem o que era o Direito. Ele me respondeu que era a garantia do exercício da possibilidade. Esse homem chama-se Galli Mathias. Comi-o". Ao buscar-se o significado do vocábulo "Galimatias" no dicionário Aurélio (1999), encontra-se "Discurso muito palavroso, confuso, obscuro e ininteligível".

A incorporação da teoria dos precedentes perpassa, portanto, pelo uso de expressões em português, inclusive para que essa seja melhor compreendida pelas partes (usuários da 
justiça) e magistrados e, assim, seja capaz de promover o fim último de acesso à justiça. Cabe aqui um elogio ao Novo Código de Processo Civil, que incorporou as expressões estrangeiras e positivou-as em português, usando os vocábulos "fundamentos determinantes", "superação" e "distinção".

Não é nova a tentativa de incorporação da teoria dos precedentes a práxis brasileira. Entretanto, alguns entraves arraigados à cultura jurisdicional do País dificultam a compreensão e aplicação dos precedentes. Percebe-se que a prática atual corresponde ao que Nunes e Bahia (2015) denominaram de aplicação "self-service" de julgados. Isso é, diante de inúmeras ementas, o julgador opta por aquela que mais se adeque à fundamentação, sem considerar as razões determinantes do julgado escolhido, no intuito de lograr êxito no alcance das metas às quais é submetido pelo sistema jurídico.

No mesmo sentido Lênio Streck ${ }^{1}(2004)$ incansavelmente denuncia o que chama de "commonlização" do direito pátrio e, assim, acentua diversas críticas ao modo como o Brasil lida (tanto nos âmbitos da doutrina, quanto da prática) com a teoria dos precedentes. E o diagnóstico é lamentável. Utilidade e eficiência tornaram-se os grandes motes que justificam a aplicação de ementas, súmulas, julgamentos por casos repetitivos, entre outros. Quão mais mecânica for a atividade jurisdicional, mais adequada ao sistema jurídico estabelecido. De fato, é como se "o Brasil passasse por um momento de preocupação voltado ao atendimento de metas, e isso, concessa venia, tomou conta dos Tribunais. O maior papel de tão relevante instituição [...] vem sendo relegado ao preenchimento de estatísticas". (TOVAR; MOREIRA, 2016, p.2).

Em interessante e profunda pesquisa sobre a aplicação prática dos precedentes no direito brasileiro coordenada por Thomas Bustamante (2015), apontam-se inúmeros problemas que estão na origem da aplicação de precedentes, como, por exemplo, o anacronismo de certas súmulas e o desrespeito, quando de sua elaboração, aos requisitos estabelecidos pela Constituição (isso significa, por óbvio, súmulas vinculantes que já nascem eivadas de vício, mas que ainda assim vêm sendo aplicadas pelos magistrados).

Além dessas feições, a dissociação da súmula e dos acórdãos em relação aos aspectos fáticos do caso-precedente distorce a noção fundante da teoria dos precedentes: a de que são as particularidades do caso que devem guiar sua aplicação (JUNQUILHO; FREITAS, 2016). O Brasil ainda carece da compreensão do "case law" ou seja, de que o direito formado com o precedente advém do julgamento de um caso e, dessa forma, não pode ser considerado como um enunciado legal geral e abstrato. Como vem há muito defendendo Streck (2008, p. 176) "o 'precedente' não cabe no enunciado!". Assim sendo, é função do intérprete avaliar os pormenores fático-jurídicos que particularizam o precedente, os quais determinarão a medida de sua utilização nos casos subsequentes.

Ao Poder Judiciário, nesse sentido, cabe conscientizar-se do papel institucional democrático que exerce, o que é fundamental para o melhor desenvolvimento da teoria dos

\footnotetext{
${ }^{1}$ Recentemente, inclusive, o autor publicou uma série de artigos no sítio Conjur em que critica a forma como a doutrina vem se posicionando acerca da aplicação da teoria dos precedentes ao Novo Código de Processo Civil.
} 
precedentes. Nesse contexto é que se entende ser necessária a conformação dialética do exercício da jurisdição no Brasil, ao genuíno modelo de precedentes.

E aqui um cuidado deve ser tomado: a antropofagia não significa adequar a teoria dos precedentes da common law ao modelo - admita-se - fracassado, que se aplica atualmente no Brasil. Trata-se do caminho oposto, ainda que considerado mais difícil. Porém, desde o giro linguístico ${ }^{2}$, ninguém pode afirmar que a tarefa interpretativa é fácil. $E$ não é à toa que Dworkin (1999) define como esforço "hercúleo", o ideal da tarefa e do exercício jurisdicional. Ou seja, trata-se de incorporar definitivamente a teoria dos precedentes com a intenção precípua de preservar a integridade, coerência e estabilidade (art. 926 CPC/15), superando-se a ideia contemporânea de que os precedentes servem tão somente para 'redução da carga de trabalho'.

O novo paradigma processual civil reafirma, então, à luz da Constituição compromisso com a integridade e a necessidade de fundamentação das decisões proferidas pelo Estado. Isso é,

[...] Compreender que o microssistema de precedentes no Novo CPC coloca a necessidade dos Tribunais não apenas uniformizarem jurisprudência, mas que esta seja mantida "estável, íntegra e coerente" é mostrar que a nova lei preocupa-se que a aplicação do Direito se dê de forma a se gerar previsibilidade nos julgamentos e, ao mesmo tempo, que o uso de julgados anteriores se dê de maneira a problematizar o uso dos mesmos face o caso que se tem a julgar (NUNES; PEDRON; BAHIA, 2015, p.6).

Com o CPC/15, espera-se que "maior valia terão os aportes da common law e da hermenêutica jurídica na interpretação de precedentes, para que se possa resgatar a facticidade e resistir à objetificações e conceitualizações" (RAMIRES, 2010, p. 86). Aliás, anseia-se que se possa alcançar o sentido profundo que a teoria dos precedentes quer revelar e que vai muito além da padronização decisória.

Com efeito, conclui-se que o "Matriarcado de Pindorama" (termo usado por Oswald de Andrade para designar o Brasil) deve se apropriar da cultura dos precedentes absorvendo o que dela se pode extrair de melhor, para, então, aplicá-la ao país. É fundamental a compreensão de que essa teoria não é a panaceia de todos os males do Judiciário. Todavia, serve ela como premissa que intenciona conformar as decisões judiciais às diretrizes basilares do Estado Democrático de Direito.

Sabe-se que não há como transportar uma teoria sem adaptá-la aos fatores culturais do país. Logo, é importante que o hibridismo antropofágico, seja feito de forma responsável, de modo que se concretize "o resgate hermenêutico da compreensão" (TOVAR; MOREIRA, 2016) e não se pretenda reduzir a compreensão do papel dos precedentes sob a ultrapassada ótica positivista, como se fossem enunciados mecanicamente aplicáveis.

\section{PRECEDENTES NA SISTEMÁtICA DO NOVO CPC: EXPECTATIVA DE} MUDANÇAS (?)

\footnotetext{
${ }^{2}$ Cabe mencionar que o movimento do giro linguístico, conforme afirmam Tovar e Moreira (2016, p. 7) "inaugura um novo paradigma para a filosofia; a linguagem até então vista como uma terceira via que liga o sujeito ao objeto, passa a ser vista como a esfera de fundamento de todo o pensar".
} 
Conforme se argumentou, é equivocado pensar que o $\mathrm{CPC} / 15$, inaugura um modelo de respeito aos precedentes no Brasil. A obediência à jurisprudência (precedentes), segundo Barbosa Moreira (2005), é fator que se evidencia desde o Império, assim como na Constituição Republicana de 1891. A importação de um modelo adequado de utilização de precedentes judiciais, torna-se, assim, cada vez mais necessária para o controle da fundamentação judicial, diminuição da discricionariedade, estabilidade do sistema e igualdade formal e material de tratamento dos casos.

Diante da percepção dessa necessidade, paulatinamente foram sendo introduzidas, na Constituição e em legislação infraconstitucional, diversas técnicas processuais que viabilizassem a aplicação dos precedentes no ordenamento brasileiro. Nesse contexto, diversos autores enumeram consecutivas reformas no âmbito do direito processual civil, as quais propiciam a gradual inserção de elementos da teoria dos precedentes no país.

Mas, para além das mudanças inseridas no Código de Processo Civil, à Constituição de 1988 também foram fixadas alterações expressivas. As mais significativas, foram inseridas por meio da Emenda Constitucional (EC) n. 45/04. Esta EC, dentre distintas transformações, instituiu a súmula vinculante, por meio do art. 103-A; o mecanismo da repercussão geral no art. 102, §3; ; além de ter estabelecido efeito erga omnes e eficácia vinculante às decisões do STF em relação aos demais órgãos do Poder Judiciário e todas as esferas da Administração Pública, em sede de controle concentrado de constitucionalidade.

O Novo Código de Processo Civil, inserido nesse contexto de intensas e rápidas transformações, surge na busca de uma reestruturação sistêmica e traz diversos sinais que demonstram a adoção definitiva do modelo de precedentes pelo Brasil. Busca-se, dessa forma, um paradigma processual civil que esteja em plena consonância com a Constituição Federal e que seja capaz de reformular o modo desvirtuado como enraizou-se a aplicação de precedentes no Brasil.

\section{O “NÚCLEO” DO MODELO DE PRECEDENTES NO CPC/2015}

O CPC/15, apresenta uma proposta "coerente e compromissada com um modelo de precedentes amplo e fundamentado nas premissas da racionalidade, estabilidade, coerência, vinculação aos fatos da causa" (ZANETI JÚNIOR, 2016, p. 343). Existem diversos dispositivos que demonstram a assunção da teoria dos precedentes pelo $\mathrm{CPC} / 15$. Dentre eles, podem ser citados alguns:

(i) Art. 12, II, III, VI, do CPC/15, que exclui a aplicação da ordem cronológica dos julgamentos em casos de julgamento de processos em bloco, para aplicação de tese jurídica firmada em julgamento de casos repetitivos, no julgamento de casos repetitivos ou de incidente de resolução de demandas repetitivas e nas decisões monocráticas do relator previstas no art. 485 e nos incisos IV e $V$ do art. 932 do CPC/15;

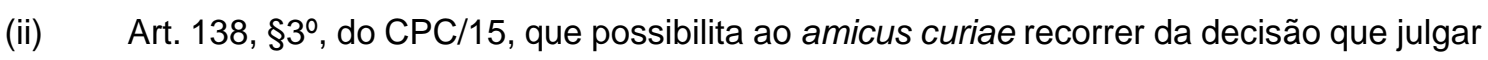
o incidente de resolução de demandas repetitivas. Isso é, o CPC/15 reconhece a importância da 
participação democrática de terceiros alheios ao processo, em decisões capazes de formar precedentes;

(iii) Art. 311, II do CPC/15, que autoriza a chamada 'tutela de evidência' nos casos em que houver "precedente do STF ou do STJ ou jurisprudência firmada em incidente de resolução de demandas repetitivas nos Tribunais de Justiça ou nos Tribunais Regionais Federais" (MARINONI; ARENHART; MITIDIERO, 2015, p. 322);

(iv) Art. 332, I a IV, que preveem como caso de improcedência liminar do pedido hipóteses em que o mesmo contrariar uma série de precedentes definidos pelo legislador.

(v) Art. 525, §§ 12 e seguintes e art. 535, §5 e seguintes, que preveem casos de inexigibilidade da obrigação reconhecida em título executivo judicial fundado em lei ou ato normativo considerado inconstitucional pelo STF, ou fundando em aplicação ou interpretação da lei ou ato normativo tido pelo STF como incompatível com a Constituição Federal, em controle de constitucionalidade concentrado ou difuso.

Observa-se que esses são apenas alguns dos exemplos de dispositivos que formalizam a teoria dos precedentes. Além desses, considera-se que os artigos 489 , $\S^{\circ}$, $\mathrm{V}$ e VI, 926 e $927^{3}$ são capitais para compreensão de um adequado modelo de precedentes, formando o que se pode chamar de "núcleo", que serve de base para os momentos de formação, aplicação e superação. Daí porque são considerados nucleares, pois cumprem essa função de guiar a forma como devem ser utilizados os precedentes nos casos em espécie, seja em tutela de evidencia, em julgamentos de casos repetitivos, nos casos de improcedência liminar ou nas demais situações em que se prevê seu uso.

\subsection{Art. 489, §1ํ, V e VI do CPC/15: a vinculação vertical}

O art. 489 do CPC/15 está inserido no Capítulo XII "Da Sentença e da Coisa Julgada", Seção II "Dos elementos e dos efeitos da sentença" e dispõe sobre o que o legislador considerou serem os elementos essenciais da sentença (relatório, fundamentação e dispositivo). Trata-se de um dos artigos centrais do Novo Código, inclusive porque $\circ$ § ${ }^{\circ}$ aborda a fundamentação de qualquer decisão judicial e não apenas de sentenças.

Ora, a motivação cumpre papel endo e extraprocessual, uma vez que serve como garantia de que os fundamentos das partes foram levados em consideração, assim como possibilita a fiscalização democrática da decisão estatal (TARUFFO, 2015). O §1ํㅡㄹ é a pormenorização do art. 93, IX da Constituição Federal, ao impor as balizas de como deve se desenvolver a fundamentação. No texto, ao invés de enumerar como deve ser fundamentada uma decisão o que, de fato, seria inviável, preferiu-se dispor quando o sistema avalia que uma decisão judicial não será considerada fundamentada, ou seja, poderá ser passível de anulação (SILVA, 2013).

Mas, o que interessa nesse estudo são especialmente os incisos V e VI do $\S 1^{\circ}$ do art. 489, os quais "no âmbito do dever de motivação das decisões judiciais, têm por evidente finalidade incrementar o controle sobre a aplicação dos precedentes jurisprudenciais" (ROQUE,

\footnotetext{
${ }^{3}$ Além desses artigos, considera-se também que os artigos 10 e 371 do CPC/15 como norteadores de toda a atividade jurisdicional de fundamentação decisória.
} 
2013, p. 258). Estabelece, portanto, a vinculação vertical e seu modo de operação nas decisões judiciais. $\mathrm{O} \S 1^{\circ}$ inciso $\mathrm{V}$ do art. 489, assim dispõe:

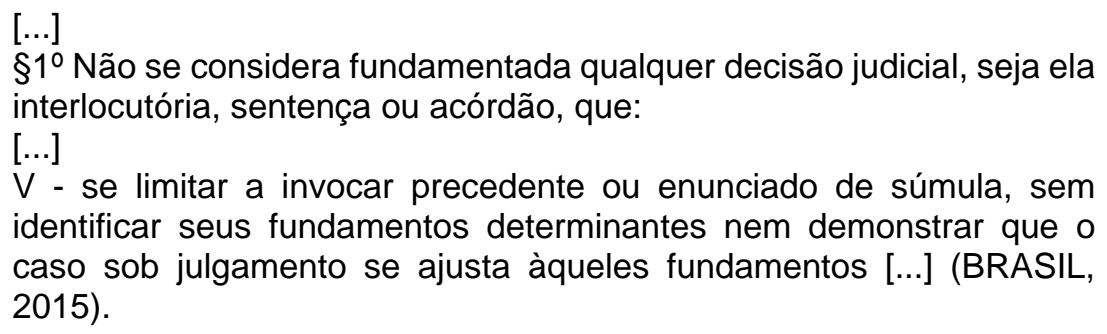

A legislação usa o conceito "fundamentos determinantes", que explicita as razões fundamentais do julgado e compõem o arcabouço fático-jurídico da decisão. Nesse sentido, trazse ao texto legal algo que é elementar à teoria dos precedentes: o aspecto de que o caso precedente e seus aspectos fundantes não podem ser desconsiderados e destacados de contexto, quando de sua aplicação ao caso futuro. As (des)semelhanças do caso, devem ser rigorosamente explicitadas pelo juiz submetido verticalmente ao precedente. Por essa razão, é fundamental a compreensão de que ainda que os fundamentos determinantes reclamem universalidade, esses somente serão estabelecidos e identificados de modo construtivo, por meio da adaptabilidade das questões princpiológicas trazidas no precedente ao fato considerado (DERZI; BUSTAMANTE, 2013).

Assim sendo, todo aquele que está submetido ao precedente, assume o ônus de reconstrução da norma precedente, em um trabalho comparatístico que deve ser realizado à luz do caso concreto sob julgamento e levando-se em consideração os fundamentos determinantes prévios. Isso é, assume-se a singularidade de cada caso e busca-se o aprofundamento nas razões determinantes do precedente para a realização da checagem de similaridades entre ambos, o que determinará a decisão. Aplicar precedentes, de modo algum constitui "simplesmente alinhar julgados - condensados ou não em súmulas - sem individualizar as suas origens, os seus significados e a pertinência que guardam com o caso concreto. " (MARINONI; ARENHART; MITIDIERO, 2015, p. 493-494).

Há que se observar, nesse sentido, que "as súmulas somente podem ser adequadamente compreendidas à luz da leitura dos precedentes e dos fundamentos determinantes adotados pela maioria dos julgadores" (ZANETI JÚNIOR, 2016, p. 351). A aplicação do enunciado sumular, desacompanhado de suas circunstâncias geradoras, é forma de desrespeito à teoria dos precedentes ou desconhecimento da forma de sua aplicação prática. Isso porque, a partir do $\mathrm{CPC} / 15$, considera-se formalmente nula, pois não fundamentada, a decisão que empregar precedente sem evidenciar os motivos pelos quais o caso é similar a esse e, portanto, merece a aplicação dos mesmos fundamentos determinantes.

$\mathrm{O} \S 1^{\circ}$, inciso $\mathrm{VI}$, do art. 489, preceitua que

[...]

$\S 1^{\circ}$ Não se considera fundamentada qualquer decisão judicial, seja ela interlocutória, sentença ou acórdão, que: 


\section{$[\ldots]$ \\ $\mathrm{VI}$ - deixar de seguir enunciado de súmula, jurisprudência ou precedente invocado pela parte, sem demonstrar a existência de distinção no caso em julgamento ou a superação do entendimento. (BRASIL, 2015)}

Nota-se que o inciso VI trata das hipóteses de distinção e superação. Sabe-se que a vinculação vertical trata-se do dever dos magistrados hierarquicamente inferiores, de "levar em consideração o precedente, com fundamento nos princípios da universalizabilidade e da imparcialidade na atividade judiciária" (BUSTAMANTE, 2012, p. 389). Esse dever é temperado, todavia, nas hipóteses estritas e justificadas de distinção e superação. Assim, toda vez que o julgador do caso concluir que o precedente invocado pela parte é substancialmente diverso daquele que se julga, assume a responsabilidade de evidenciar as razões pelas quais 0 precedente não se aplica ao fato.

A outra possibilidade em que o julgador pode deixar de seguir o precedente apontado pelas partes é a superação. Desse modo, observa-se que as tradições que adotam a teoria dos precedentes judiciais, admitem que em determinado momento histórico e mediante 0 reconhecimento de determinadas circunstâncias da cultura jurídica, o precedente possa ser superado. A regra-de-ouro do procedimento de argumentativo de superação é "sempre que um juiz ou tribunal for se afastar de seu próprio precedente, este deve ser levado em consideração, de modo que a questão do afastamento do precedente judicial seja expressamente tematizada" (BUSTAMANTE, 2012, p. 388).

Dessa forma compreende-se que a vinculação aos precedentes não significa obediência 'cega' ao que preceitua o caso anterior decidido pelas Cortes Superiores, por instâncias julgadoras hierarquicamente inferiores (e nesse ponto supera-se, inclusive, o temor de alguns de que a teoria dos precedentes engessaria os juízes, tornando-os 'meros' repetidores de enunciados). Ao contrário, a vinculação aos precedentes é sempre crítica, no sentido de que depende incondicionalmente de pormenorizada análise fático-jurídica das circunstâncias, tanto das razões determinantes, quanto do caso concreto, para que daí explicite-se na fundamentação as motivações de aplicação, superação ou distinção.

\subsection{Art. 926 e 927: a vinculação horizontal e vertical}

Os artigos 926 e 927 do $\mathrm{CPC} / 15$, trazem diretrizes para aquele que estabelece 0 precedente. Nesse sentido, organizam a vinculação horizontal ou autovinculação, por meio da qual a corte criadora do precedente deve segui-lo reiteradamente na análise de futuros casos similares, e também a vertical. Assim prescreve o artigo 926:

Art. 926. Os tribunais devem uniformizar sua jurisprudência e mantêla estável, íntegra e coerente.

$\S 10 \mathrm{Na}$ forma estabelecida e segundo os pressupostos fixados no regimento interno, os tribunais editarão enunciados de súmula correspondentes a sua jurisprudência dominante.

$\S 20$ Ao editar enunciados de súmula, os tribunais devem ater-se às circunstâncias fáticas dos precedentes que motivaram sua criação. (BRASIL, 2015) 
O Art. 926 do CPC/15 preocupa-se com a preservação da unidade interpretativa, por meio da vinculação horizontal. Nesse sentido, muito mais que uniformizar a "jurisprudência", trata do dever dos tribunais de alcançar a integridade por meio de precedentes. E aqui há que se destacar que o artigo faz referência a "tribunais", o que inclui tanto o Supremo Tribunal Federal e o Superior Tribunal de Justiça, como também os Tribunais de Justiça Estaduais e Federais componentes da organização judiciária da República brasileira. Discorda-se, portanto, daqueles que - como Mitidiero (2014) e Marinoni (2015a) - defendem que as decisões dos Tribunais que não são de vértice são apenas jurisprudência e, portanto, têm mero valor persuasivo eis que a unidade do direito seria garantida apenas pelas Cortes Superiores.

Ora, de fato as Cortes Supremas são aquelas cuja atividade precípua é formar precedentes. Mas, até que determinada circunstância fático-jurídica seja analisada pelas Cortes Superiores, os demais Tribunais formam precedentes que devem vincular suas respectivas jurisdições. Pensar de modo diverso seria ignorar o que preceituam os art. 926 e 927 do CPC/15, assim como significaria permitir a barbárie interpretativa no âmbito dos estados da Federação, em questões que não chegassem às Cortes de Vértice.

Além disso, deve-se ter sempre em mente o que representa a adoção do modelo de precedentes. O modelo de precedentes, não tem sua justificativa baseada na autoridade do juízo que o profere, mas sim, em sua importância para integridade do sistema. Todo e qualquer Tribunal deve, portanto, manter a unidade do ordenamento por meio de precedentes que garantam a estabilidade, a integridade e a coerência.

A estabilidade, é caracterizada por Gáscon (2012) como uma virtude fomentada pelos precedentes, cujo significado é possibilitar aos cidadãos que guiem suas ações com base na análise das consequências anteriormente definidas por juízes em casos semelhantes. A estabilidade gera, portanto, o dever de manutenção do precedente. Isso porque, por meio da estabilidade, assume 0 intérprete pesado ônus argumentativo que justifique hipótese de superação ou distinção - consideradas como situações excepcionais de não aplicação do precedente - afim de que a sociedade tenha sua confiança protegida.

A integridade, é referência trazida por diversos autores. Para Dworkin (2000, p. 230) a integridade "promove a união da vida moral e política dos cidadãos". A noção de integridade trazida por Dworkin "[...] pressupõe um modelo de comunidade segundo o qual os indivíduos que compõem essa comunidade compartilham determinada compreensão acerca da moral e dos fundamentos da convivência em sociedade (BUSTAMANTE, 2012, p.136).

A ideia de integridade envolve, portanto, a percepção da dimensão moral comunitária compartilhada; de bases mínimas comuns ao senso moral existentes no seio da sociedade, capazes de formar os pilares da formação dos direitos. A atividade interpretativa do direito, nesse sentido, que é capaz de gerar precedentes, deve ser realizada de modo a proporcionar a manutenção da unidade da tradição ou do ordenamento jurídico compreendido de forma ampla, preservando sua integridade.

Por fim a coerência deve ser entendida no sentido de consistência (termo cunhado por MacCormick, 2003). Ou seja, é o dever de que a atividade interpretativa dos magistrados não possibilite a existência de decisões contraditórias coexistentes. Para Martins, Roesler e Jesus 
(2011, p. 214) MacCormick "interpreta a consistência como sendo satisfeita pela não contradição. Dessa forma, olhando para um grupo de proposições, o conjunto delas é consistente quando não se observa contradição de umas com as outras".

Além disso o artigo "marca a vedação de que o tribunal edite enunciado de súmula que não se atenha às circunstâncias fáticas dos casos-precedentes" (ZANETI JÚNIOR, 2015, p. 364). Ora, a teoria dos precedentes surge como case law (direito formado pela análise de casos concretos). Seria um contrassenso permitir que a criação e aplicação de enunciado sumulares se destacasse das circunstâncias dos casos concretos que the deram origem. Esse equívoco é inaceitável sob a égide do no Novo Código de Processo Civil.

O artigo 927 completa o "núcleo-base" do sistema de precedentes instaurado pelo Novo CPC, ao dispor:

Art. 927. Os juízes e os tribunais observarão:

I - as decisões do Supremo Tribunal Federal em controle concentrado de constitucionalidade;

II - os enunciados de súmula vinculante;

III - os acórdãos em incidente de assunção de competência ou de resolução de demandas repetitivas e em julgamento de recursos extraordinário e especial repetitivos;

IV - os enunciados das súmulas do Supremo Tribunal Federal em matéria constitucional e do Superior Tribunal de Justiça em matéria infraconstitucional;

V - a orientação do plenário ou do órgão especial aos quais estiverem vinculados.

$\S 10$ Os juízes e os tribunais observarão o disposto no art. 10 e no art. 489 , § 10, quando decidirem com fundamento neste artigo.

$\S 20$ A alteração de tese jurídica adotada em enunciado de súmula ou em julgamento de casos repetitivos poderá ser precedida de audiências públicas e da participação de pessoas, órgãos ou entidades que possam contribuir para a rediscussão da tese.

$\S 30 \mathrm{Na}$ hipótese de alteração de jurisprudência dominante do Supremo Tribunal Federal e dos tribunais superiores ou daquela oriunda de julgamento de casos repetitivos, pode haver modulação dos efeitos da alteração no interesse social e no da segurança jurídica.

§ 40 A modificação de enunciado de súmula, de jurisprudência pacificada ou de tese adotada em julgamento de casos repetitivos observará a necessidade de fundamentação adequada e específica, considerando os princípios da segurança jurídica, da proteção da confiança e da isonomia.

$\S 50$ Os tribunais darão publicidade a seus precedentes, organizandoos por questão jurídica decidida e divulgando-os, preferencialmente, na rede mundial de computadores (BRASIL, 2015).

Vê-se que o artigo 927 do CPC/15 estabelece um rol de precedentes de observância obrigatória por juízes e tribunais. Primeiramente é necessário lembrar que a aplicação de tais hipóteses somente deve se dar quando de fato o juiz ou tribunal estiver diante de um precedente, assim como não poderá olvidar-se dos fundamentos determinantes que levaram à sua formação (são as razões determinantes que vinculam os magistrados).

Tendo sempre em mente essa compreensão, nota-se que os enunciados de súmula vinculante; os acórdãos formados em incidente de assunção de competência ou de resolução de demandas repetitivas e em julgamento de recursos extraordinário e especial repetitivos e as demais hipóteses do artigo 927, devem ser aplicadas à luz dos arts. 489, §1ํe 10. É dizer, 
sempre por meio de rigorosa avaliação que contemple as peculiaridades do caso-precedente e do caso-julgado e suas similitudes.

O artigo traz interessante previsão no $\S 2^{\circ}$, ao possibilitar que a decisão de superação do precedente seja precedida de audiências públicas ou de contribuição de amicus curiae. A participação democrática na superação do precedente é vista como salutar, pois possibilita abertura ao pluralismo em decisão que terá potencial para afetar diversos julgamentos similares subsequentes.

O §3ำ do artigo 927, traz a permissão de modulação dos efeitos da alteração da tese jurídica do precedente na hipótese de alteração da jurisprudência dominante do STF, dos tribunais superiores ou daquela oriunda de julgamento de casos repetitivos, com vistas a proteção do interesse social e da segurança jurídica. Assim é que a técnica de modulação dos efeitos, originariamente prevista para o controle de constitucionalidade concentrado, pode ser realizada pelos tribunais, quando esses modificarem a tese dos precedentes.

Por último, os parágrafos $4^{\circ}$ e $5^{\circ}$ consubstanciam a ideia de que a modificação do precedente deve se dar de modo a preservar a necessidade de fundamentação adequada e específica, considerando os princípios da segurança jurídica, da proteção da confiança e da isonomia, além de ratificar-se a obrigação de publicidade aos precedentes. O imperativo de fundamentação na alteração de determinado precedente é garantia da obrigação em se "justifica a necessidade da sua revogação, apresentando-se as razões pelas quais ele não pode mais prevalecer" (MARINONI, 2015b, p.2080). E a publicidade é técnica que garante a efetiva vinculação dos precedentes, a partir do momento em que se tornam conhecidos por quem está vinculado.

O que se pode observar a partir da análise do modelo de precedentes reforçado pelo $\mathrm{CPC} / 15$ é que esse acende uma oportunidade de se repensar a teoria dos precedentes ao Brasil. Ao robustecer a necessidade do ônus argumentativo no exercício da jurisdição, quando da criação, (des)aplicação ou superação de um precedente, o CPC/15 reafirma o compromisso dos meios de processo e procedimento, com a Constituição em especial com o artigo 93, IX. Nesse sentido, a partir da criação de um novo paradigma processual civil, é necessário redescobrir "o embasamento de suas normas, em especial, quando se pretende instituir um modelo normativo contrafático (corretivo dos atuais equívocos) que leve a sério o direito jurisprudencial, tanto na formação quanto na aplicação correta dos precedentes" (NUNES; PEDRON; BAHIA, 2015, p. 1).

\section{CONSIDERAÇÕES FINAIS: POR QUE É POSSÍVEL TER ESPERANÇA?}

Ao final do trabalho é interessante revisitar a questão inicial que motivou a investigação. É possível esperar um porvir de cumprimento da integridade por meio da aplicação dos novos ditames positivados no $\mathrm{CPC} / 15$ ?

O novo paradigma processual civil, ao rever diversos aspectos da fundamentação judicial e do modo de utilização da teoria dos precedentes, incluindo, inclusive como seus escopos (núcleo-base) a busca da integridade, a coerência e a estabilidade, parece traduzir-se na oportunidade de um repensar a jurisdição. Esse meditar, inclui a imperiosa deglutição da tradição 
do "case-law" e da noção de busca da integridade no direito a partir da antropofagia das noções trazidas pelos precedentes, para que se concretize sua definitiva adequação aos aspectos que traduzem a jurisdição brasileira.

Não obstante essa confiança no novo código, tem-se em mente a importante noção de que o texto sempre depende da interpretação para tornar-se norma e que, portanto, é em sua aplicação que poderá se definir se o CPC/15 cumpriu com as expectativas que por ora se concluem de sua observação. Mas isso, sabe-se, somente a práxis poderá confirmar ou refutar.

"Tupi or not Tupi?". Aceitarão, jurisdicionados e julgadores, o desafio imposto pelo Novo Código de Processo Civil, de concretizar e amoldar em definitivo a teoria dos precedentes à tradição brasileira? Eis a questão.

\section{REFERÊNCIAS}

ALMEIDA, Maria Candida Ferreira de. Só a antropofagia nos une. Clacso - Conselho Latinoamericano de Ciências Sociales. In: Consejo Latinoamericano de Ciencias Sociales (CLACSO). Cultura política e sociedade: perspectivas latino-americanas, 2005. Disponível em: <http://biblioteca.clacso.edu.ar/clacso/gt/20100912055926/5FerreiradeAlmeida.pdf >. Acesso em: 15 set. 2015.

ANDRADE, Oswald de. Manifesto Antropófago. Disponível em: <http://www.ufrgs.br/cdrom/oandrade/oandrade.pdf>. Acesso em: 12 jul. 2015.

ANDRADE, Valdeciliana Ramos de; BUSSINGER, Marcela de Azevedo. A linguagem jurídica como estratégia de Acesso à Justiça: uma análise do processo de interação linguística entre 0 magistrado e as partes. Rev. Panóptica, v. 1, n.1, 2006, p. 15-21.

ATAÍDE JÚNIOR, Jaldemiro Rodrigues. Precedentes vinculantes e irretroatividade do direito no sistema processual brasileiro: os precedentes dos Tribunais Superiores e sua eficácia temporal. Curitiba: Juruá, 2012.

BRASIL. Constituição da República da República Federativa do Brasil. Disponível em: $<$ http://www.planalto.gov.br/ccivil_03/Constituicao/Constituica067.htm>. Acesso em: 18 nov. 2015.

Lei № 13.105, de 16 de março de 2015. Código de Processo Civil. Brasília. Disponível em: < http://www.planalto.gov.br/ccivil_03/_Ato2015-2018/2015/Lei/L13105.htm>. Acesso em: 21 abr. 2015.

BUSTAMANTE, Thomas da Rosa de. Teoria do precedente judicial: a justificação e a aplicação de regras jurisprudenciais. São Paulo: Noeses, 2012.

(Coord.). A força normativa do direito judicial: uma análise da aplicação prática do precedente no direito brasileiro. Brasília: Conselho Nacional de Justiça, 2015. Disponível em: <https://www.academia.edu/13250475/A_for\%C3\%A7a_normativa_do_direito_judicial__Justi\%C3 \%A7a_Pesquisa_-_UFMG >. Acesso em: 19 out. 2016.

DERZI, Misabel de Abreu Machado; BUSTAMANTE, Thomas da Rosa de. O efeito vinculante e o princípio da motivação das decisões judiciais: em que sentido pode haver precedentes vinculantes no direito brasileiro? In: FREIRE, Alexandre. et al.(Org.). Novas Tendências do Processo Civil: estudos sobre o projeto do novo código de processo civil. Salvador: Juspodivm, 2013. p. 331-360.

DINIZ, Júlio. Antropofagia e Tropicália - devoração/ devoção. Colóqui Brésil/Europe: repenser le mouvement antropophagique. Collége Internacional de Philosophie: Paris, 2007 Disponível em: $<$ http://www.maxwell.vrac.pucrio.br/NELIM/ensaios_artigos/julio_antropogafiaetropicalia.pdf>. Acesso em: 09 set. 2015. 
DWORKIN, Ronald. O Império do Direito. Tradução de Jefferson Luiz Camargo. São Paulo: Martins Fontes, 1999.

FERREIRA, A. B. H. Aurélio século XXI: o dicionário da Língua Portuguesa. 3. ed. rev. e ampl. Rio de Janeiro: Nova Fronteira, 1999. 2128p.

GÁSCON, Marina. Rationality and (self) precedent: brief considerations concerning the grouding and implications of the rule of self precedent. In: BUSTAMANTE, Thomas; PULIDO, Carlos Bernal (ed). On the Philosophy of Precedent: Proceedings of the 24th World Congress of the International Association for Philosophy of Law and Social Philosophy. Beijing, 2009, v.III. Stuttgart/Sinzheim: Franz Steiner Verlag: Nomos, 2012.

GENEROSO, Viviane Horta. Devoração ou hospitalidade? Rev. Latinoam. Psicopat. Fund., São Paulo, n. 16, mar. 2013, p. 160-171.

JUNQUILHO, Tainá Aguiar; FREITAS, Elias Canal. As diretrizes da fundamentação judicial e o modo de aplicação da teoria dos precedentes no Art. 489, §1ㄴ, V e VI do CPC 2015. In: DIAS, Luciano Souto (Coord.). Temas controvertidos no Novo Código de Processo Civil. Curitiba: Juruá, 2016. p.149-168.

LADEIRA, Aline Haddad; BAHIA, Alexandre. O precedente judicial em paralelo a súmula vinculante: pela (re)introdução da faticidade ao mundo jurídico. Revista de Processo, São Paulo, ano 39, n. 234, ago.2014, p. 275-301.

LARAIA, Roque de Barros. Cultura: um conceito antropológico. 21 ed. Rio de janeiro: Jorge Zahar Editor, 2007.

MACCORMICK, D. Neil. Rhetoric and the rule of law. Legal reasoning and legal theory [1978]. Reprinted. New York: Oxford University Press, 2003.

MARINONI, Luiz Guilherme. Julgamento nas Cortes Supremas: precedente e decisão do recurso diante do Novo CPC. São Paulo: Revista dos Tribunais, 2015a.

Da ordem dos processos e dos processos de competência originária dos tribunais. In: WAMBIER, Teresa Arruda Alvim et. Al., (Coord.). Breves Comentários ao Novo Código de Processo Civil. São Paulo: Editora Revista dos Tribunais, 2015b, p. 2072-2083.

; ARENHART, Sérgio Cruz; MITIDIERO, Daniel. Novo Código de Processo Civil Comentado. São Paulo: Revista dos Tribunais, 2015.

MARTINS, Argemiro Cardoso Moreira; ROESLER, Cláudia Rosane; JESUS, Ricardo Antonio Rezende de. A noção de coerência na teoria da argumentação jurídica de Neil MacCormick: caracterização, limitações, possibilidades. Revista Novos Estudos Jurídicos, v. 16, n. 2, 2011, p. $207-221$

MITIDIERO, Daniel. Cortes Superiores e Cortes Supremas: Do Controle à Interpretação, da jurisprudência ao Precedente. 2 ed. rev. atual. ampl. São Paulo: Revista dos Tribunais, 2014.

MOREIRA, José Carlos Barbosa. Súmula, Jurisprudência, Precedente: uma escalada e seus riscos. Revista Síntese de Direito Civil e Processual, Porto Alegre: Síntese, v. 6, n. 35, p. 516, maio/jun. 2005.

NUNES, Dierle; BAHIA, Alexandre Melo Franco. Precedentes no CPC-2015: por uma compreensão constitucionalmente adequada do seu uso no Brasil. In: FREIRE, Alexandre; BARROS, Lucas Buril de Macedo; PEIXOTO, Ravi. Coletânea Novo CPC: Doutrina Selecionada. Salvador: Juspodivm, 2015.

; PEDRON, Flávio; BAHIA, Alexandre. Precedentes no Novo CPC: É possível uma decisão correta? Disponível em: <http://justificando.com/2015/07/08/precedentes-no-novo-cpce-possivel-uma-decisao-correta-/>. Acesso em: 23 set. 2016. 
RAMIRES, Maurício. Crítica à aplicação de precedentes no Direito Brasileiro. Porto Alegre: Livraria do Advogado, 2010.

ROQUE, Andre Vasconcelos. Dever de motivação das decisões judiciais e controle da jurisprudência no Novo CPC. In: FREIRE, Alexandre. et al.(Org.). Novas Tendências do Processo Civil: estudos sobre o projeto do novo código de processo civil. Salvador: Juspodivm, 2013, p.245-261.

SILVA, Beclaute Oliveira. Decisão judicial não fundamentada no Novo CPC: nas sendas da linguagem. In: FREIRE, Alexandre. et al.(Org.). Novas Tendências do Processo Civil: estudos sobre o projeto do novo código de processo civil. Salvador: Juspodivm, 2013. p. 187-202.

SILVA, Ticiano Alves e. Jurisprudência banana boat. Revista de Processo, São Paulo, ano 37, n. 209, p. 289-292, jul.2012.

SIQUEIRA, Gustavo Silveira. Pequeno ensaio sobre antropofagia jurídica: por uma sociologia histórica do direito brasileiro? Revista da Faculdade de Direito - UFPR, Curitiba, vol. 61, n. 1, jan./abr. 2016, p. $303-312$.

STRECK, Lênio Luiz. A hermenêutica jurídica e o efeito vinculante da jurisprudência no Brasil: o caso das súmulas. Boletim da Faculdade de Direito, v. LXXXII, Coimbra, 2006, p. 213-236.

Súmulas, vaguezas e ambiguidades: necessitamos de uma 'teoria geral dos precedentes'? Rev. Direitos Fundamentais e Justiça, Porto Alegre, Ano 2, n. 5, out./dez. 2008,162-185.

TARUFFO, Michele. A motivação da sentença civil. Apresentação, organização e tradução de Luiz Guilherme Marinoni e Daniel Mitidiero. São Paulo: Marcial Pons, 2015.

THEODORO JÚNIOR, Humberto; NUNES, Dierle; BAHIA, Alexandre. Breves considerações sobre a politização do Judiciário e sobre o panorama de aplicação no direito brasileiro: Análise da convergência entre o civil law e o common law e dos problemas da padronização decisória. Revista de Processo, São Paulo, ano 35, n. 189, nov. 2010, p. 9-52.

ZANETI JR., HERMES. O valor vinculante dos precedentes: o Modelo Garantista (MG) e a redução da discricionariedade judicial. Uma teoria dos precedentes normativos formalmente vinculantes. Salvador: Juspodivm, 2016.

WAMBIER, Teresa Arruda Alvim. Estabilidade e adaptabilidade como objetivos do direito: civil law e common law. Revista de Processo, São Paulo, ano 34, vol. 172, jun. 2009, p. 121-174. 